\title{
DA VIDA POBRE AO RECONHECIMENTO PELO ATO DE EMPREENDER
}

\section{FROM POOR LIFE TO RECOGNITION BY THE ACT OF JOB}

\author{
José Queiroz Cruz Filho \\ Faculdade Luciano Feijão - Sobral - CE \\ queiroz1933@hotmail.com \\ Rogeane Morais Ribeiro \\ Faculdade Luciano Feijão - Sobral - CE \\ rogeanemorais@yahoo.com.br \\ Maria do Socorro Silva Mesquita \\ Faculdade Luciano Feijão - Sobral - CE \\ socorromesquita@yahoo.com.br
}

Jan Riella

Faculdade Luciano Feijão - Sobral - CE jriella@gmail.com

Luis Emanuell de França Gonçalves Faculdade Luciano Feijão - Sobral - CE luisfran.ca@outlook.com

Submissão: 05/05/2018 Aprovação: 24/10/2018

\section{RESUMO}

Este caso para ensino relata a trajetória de um empreendedor, de 49 anos, que identificou em meio às dificuldades de uma cidade do interior do Ceará, a oportunidade de abrir seu próprio negócio no ramo de frutas. De origem humilde, deixou o interior de Riachão dos Farias, aos doze anos de idade, com destino à casa dos tios em Massapê. Apesar da mudança, teve que trabalhar desde cedo por conta da precária situação financeira da família, trabalhando como vendedor de picolé, carregador de água e lenha. Aos 37 anos, começou seu próprio negócio. A empresa teve seu início em 2005 e embora seja um negócio novo, o empreendimento já se tornou uma das principais referências no segmento de frutas da cidade. Analisando as vendas crescendo e a concorrência aumentando, o empresário decide trazer o filho caçula Queiroz Filho para ajudar na gestão da empresa, porém não sabe se acatar as decisões impostas por ele é a melhor opção. O que fazer? Investir ou não?

Palavras-Chave: Empreendedorismo. Estratégias. Processo decisório. Sucessão familiar. 


\begin{abstract}
This case study teaches the trajectory of an entrepreneur, 49, who identified amid the difficulties of a city in the interior of Ceará, the opportunity to open their own business in the fruit sector. Of humble origin, he left the interior of Riachão dos Farias, at the age of twelve, bound for his uncle's house in Massapê. Despite the change, she had to work early because of the family's precarious financial situation, working as a popsicle seller, water carrier and firewood. At age 37, he started his own business. The company started in 2005 and although it is a new business, the venture has already become one of the main references in the fruit segment of the city. Analyzing growing sales and increasing competition, the businessman decides to bring his youngest son Queiroz Filho to help manage the company, but he does not know whether to abide by the decisions imposed by him is the best option. What to do? Invest or not?
\end{abstract}

Keywords: Entrepreneurship. Strategies. Decision making process. Family succession.

\title{
Introdução
}

O caso conta a história de um jovem empreendedor, de uma cidade pequena do interior do Ceará, na área de frutas. Por conta da situação precária da família, teve que trabalhar desde cedo, iniciando seu primeiro emprego aos dez anos de idade, trabalhando em vários segmentos.

Por mais que tenha sido um trabalho árduo e necessário para ajudar a complementar a renda da família, que era compensado todas as semanas, quando levara o trocado recebido para seus pais, Queiroz decide enfrentar novos horizontes e se mudar para o Pará, estado no qual se concentra grande parte de sua família.

Com o passar do tempo, observou que os empregos ofertados naquela região não eram condizentes com a experiência e desejos de Queiroz. E também, a saudade apertava o peito à medida que os dias se passavam. Foi então que em 1991, ele decide voltar ao estado do Ceará.

Em 2005, com o incentivo e ajuda de toda a família, iniciou seu próprio negócio no ramo de frutas. A cada dia, a empresa está conseguindo atingir uma quantidade de clientes de forma acelerada e como resultado do aumento dos clientes, começam a surgir limitações. Como resultado, o negócio continua crescendo à medida que novas estratégias são implementadas. Nesse sentido, está cada vez mais preocupante saber de que forma o empreendedor conseguirá controlar o fluxo de receitas e despesas da empresa e se essa decisão imposta pelo filho caçula é realmente importante para o negócio.

Diante deste cenário o empreendedor José Queiroz vive o seguinte dilema: Permanecer com a empresa de origem? Realizar novos investimentos para o controle dos custos totais?

\section{História de um vencedor- 1968 à 1980}

José Queiroz Cruz nasceu em uma localidade conhecida como Riachão dos Farias, localizada a $15 \mathrm{~km}$ da cidade de Massapê, interior do Ceará, no dia 08 de maio de 1968. Por conta da situação precária da família e na tentativa de oferecer a ela maiores oportunidades, teve que trabalhar desde cedo, iniciando seu primeiro emprego aos dez anos de idade, juntamente com seus irmãos mais velhos.

Cidade pequena, pouca oferta de estudos e empregos e uma família consideravelmente grande, tudo era motivo de angústia e medo por parte da dona Maria Francisca Cruz e Edmilson Queiroz Cruz, os pais de Queiroz. Era necessária coragem para enfrentar os obstáculos e seguir 
forte na luta pela busca de um sustento que fosse capaz de suprir as necessidades de todos os filhos.

Filho de pais pobres e vivendo em uma cidade onde não lhe dava muita expectativa de vida, começou a ser destaque na família aos dez anos de idade, juntamente com seu pai, quando começou a frequentar os roçados em busca de alimentação para toda a família.

Em 1980, aos 12 anos de idade, deixou para trás a mãe e os irmãos, fugindo da fome, e iniciou uma nova vida com os tios, Edite e Soares, na sede da cidade, que foi acolhido com total amor e carinho. Embora as condições financeiras dos tios não fossem suficientes, eram bem melhores que aquela no qual deixara para trás. Com a nova moradia, Queiroz passou a trabalhar como vendedor de picolé, carregador de água e lenha. Trabalho árduo, mas a seu ver necessário para ajudar a complementar a renda da família, que era compensado todas as semanas, quando levara o trocado recebido para seus pais.

Após algum tempo, com a escassez de alimentos, incentivo da família e sempre ansiando ajudá-los, levou sua mãe e seus irmãos para poder morar na cidade de Massapê. Arriscou-se em vários tipos de empregos para poder oferecer a família uma condição mais digna de vida, porém não obteve êxito em seus trabalhos.

\section{Arriscando-se na vida- 1990 à 1998}

Cheio de garra e dotado de entusiasmo, Queiroz era um empreendedor destemido, que buscava a todo custo ajudar seus pais e irmãos. Conciliando a oportunidade com os boatos circulados naquela época acerca de maiores oportunidades fora do Ceará, o empresário decide, em 1990, aos 22 anos, enfrentar novos horizontes e se mudar para o Pará, estado no qual se concentra grande parte de sua família.

Passado um ano na cidade, percebeu que os empregos ofertados naquela região não eram condizentes com a experiência e desejos dele. E também, a saudade apertava o peito à medida que os dias se passavam. Foi então que em 1991, Queiroz decide voltar ao estado do Ceará.

Ao chegar em Massapê, cidade a qual passara toda a vida, e impelido pela precária situação, no qual se encontrava, e na tentativa de poupar os pais e irmãos dessas dificuldades, deu início a mais uma nova etapa de sua vida. Passara a trabalhar em um armazém como entregador e repositor, além disso, em seu tempo livre, fazia alguns "bicos", como pedreiro, garçom, assistente de arbitragem de futebol e comercializava também chapéus.

Em março de 1998, passou a trabalhar em uma feira de frutas, com o seu cunhado, Zé Olavo. Durante sete anos se dedicou fielmente a esse emprego e assim conseguiu aprender todos os caprichos de ser um bom vendedor e conhecer os clientes potenciais.

\section{Novos desafios: Um passo adiante- 2005 à 2008}

Com um olhar firme nas oportunidades que surgiam no mercado, José Queiroz, cheio de desejos e expectativas e movido por sua visão empreendedora, decide montar seu próprio negócio. Conciliando a oportunidade com a necessidade, em 2005 abre sua primeira barraca de frutas no mercado central da cidade. Após a experiência que obteve durante os sete anos de trabalho árduo, o empreendedor tinha total confiança e credibilidade por parte dos clientes. Isso fez com que conseguisse atingir uma fatia considerável de compradores para seu novo negócio.

O negócio caminhava a passos lentos, os lucros eram pequenos, e contava com o serviço apenas de um funcionário. Porém, a cada dia que passa mais clientes vão surgindo e a concorrência vai se evidenciando. Com isso, o empresário adotou algumas medidas, como 
ampliação do quadro de funcionários e do espaço de trabalho, permanecendo em uma localização centralizada, já que havia um grande movimento naquela região.

Queiroz é otimista e está sempre perseguindo novas oportunidades. Apesar de ter adotado algumas mudanças necessárias para o crescimento do negócio, alguns problemas ainda perseguiam o empreendedor. Em 2008, percebeu-se que o espaço adotado, por mais que fosse alocado em um local central da cidade, estava desfavorável para alguns comerciantes. Eis então que surge mais desafios: Como se mudar para um espaço desejado por todos comerciantes? Como pagar um aluguel que, no momento não estava nos seus planos? Como administrar todas as receitas e despesas sem nenhum controle/sistema financeiro?

Ainda assim, se viu na necessidade de empreender, de se destacar no mercado da cidade de Massapê. Estratégias foram adotadas e decisões foram tomadas.

\section{Filhos: escutá-los ou deixar a voz da experiência falar? - 2014}

No ano de 2014, o empreendedor decide chamar o seu filho, universitário de Administração, para trabalhar consigo. Seu objetivo era fazer com que o filho caçula conhecesse o negócio com mais afinco, como funcionava cada parte, desde o financeiro a uma entrega e assim, detectar possíveis problemas e alternativas.

Advindo a isso, o filho, também chamado de Queiroz, percebe que existem alguns erros na empresa de seu pai que precisam ser solucionados, como a adoção de um plano de marketing, fundamental para o negócio, e que deve ser aderido para maior conhecimento da marca, além de uma uniformização, um espaço maior onde fosse possível alocar todos os comerciantes e por fim, um sistema financeiro que fosse capaz de permitir o controle de todas as receitas e despesas da empresa.

Partindo da análise de Queiroz, o filho no qual deu total confiança sugeriu que o pai implementasse alguns novos modelos de negócio dentro da organização, para que assim a empresa se tornasse mais sólida e competitiva no cenário da cidade de Massapê. Porém, o empreendedor, cabeça dura, acredita que mudar o mínimo que seja do negócio não seria algo eficaz para o crescimento da empresa, crê que não existe vantagem em mudar um estilo de negócio que vem dando certo a décadas para um que, na sua visão, não traz vantagem nenhuma.

\section{O cenário do dilema -2017}

Queiroz é um dos feirantes mais bem-conceituados do mercado, apesar das dificuldades o empreendedor consolidou-se no mercado de frutas, tornando-se conhecido por seus diferenciais de atendimento que prezam a satisfação dos clientes. Baseado na análise do filho caçula, conquistada durante seu período de estudo no curso de Administração, a cerca de todos os seguimentos da empresa, o mesmo acredita que obter um controle financeiro, o problema de maior destaque atualmente na empresa, seria a melhor opção para seu pai adotar, já que não existe controle de receitas e despesas do empreendimento.

Porém tem medo de arriscar e não conseguir manter a clientela que atingiu durante tantos anos, para pôr a empresa nas mãos do seu filho caçula. Diante disso, vem a sua cabeça vários questionamentos: O que garante que o sistema financeiro dará certo?

Queiroz encontra-se feliz pela possibilidade de crescer com ajuda do futuro administrador da família, mas receoso pelas consequências de um sistema que, para ele, nunca existiu.

NOTAS PARA ENSINO 


\section{Objetivos Pedagógicos}

Este caso para ensino representa uma situação real na qual é enfatizada a trajetória de um empreendedor que abriu seu próprio negócio baseado nas oportunidades e experiências obtidas desde a infância. $\mathrm{O}$ caso tem o desígnio de permitir ao discente a conquista de conhecimentos e um debate e defesa de seus pontos de vista referentes às aptidões e comportamentos empreendedores. Desta forma, podem-se destacar alguns temas de aprendizagem:

- Proporcionar aos alunos discussões sobre os conceitos de empreendedorismo, estratégias e sucessão familiar;

- Identificar as características empreendedoras do empresário;

- Propiciar uma reflexão sobre os aspectos que influenciaram o empreendedor a identificar uma oportunidade de negócio e de que forma pôr em prática essa oportunidade;

- Identificar como se compõe o processo de identificação de oportunidade;

- Possibilitar um debate avaliando as potencialidades e fragilidades existentes no negócio;

- Permitir a observação das dificuldades enfrentadas em se trabalhar com membros da família;

- Propor soluções viáveis para a resolução do dilema.

\section{Área de conhecimento e público a quem se destina}

Sugere-se que o caso seja utilizado com os alunos em cursos de graduação em Administração ou áreas afins, especificamente nas disciplinas de Empreendedorismo, Estratégia, Processo decisório e Sucessão Familiar. Justifica-se o uso do caso nessas disciplinas por estimular os alunos a refletirem e relacionarem o contexto teórico com a prática gerencial a partir de uma análise sobre os comportamentos, perfil e características empreendedoras, e a capacidade de tomada de decisão do gestor que atua em um segmento familiar cada vez mais competitivo.

\section{Protagonista}

Para a discussão do caso, os discentes irão ter a possibilidade de assumir três papeis distintos, ou seja, apresentarão pontos de vista de acordo com cada personagem: 1). Do empreendedor José Queiroz, que deseja controlar seu negócio com uma plataforma de controle de caixa, porém não sabe se é a melhor opção. 2). Dos clientes, no qual avaliam as vantagens e desvantagens desse empreendimento na cidade e 3). Do filho Queiroz Filho, estudante de Administração, no qual deseja implantar uma ferramenta de fluxo de caixa na empresa. Como segunda alternativa, a turma poderá ser dividida em três grupos, de modo a discutir conforme as três perspectivas.

\section{Obtenção dos dados}

O presente caso para ensino é baseado em uma história real. As informações descritas no decorrer do texto foram coletadas a partir de entrevistas com o proprietário do negócio, 
familiares e clientes, em agosto de 2017. Os nomes e a ordem cronológica citada no decorrer da narrativa são reais, e dispõem da permissão do protagonista para utilização e publicação.

\section{Estratégias de Ensino}

Como sugestão para a compreensão e análise do caso, recomenda-se que o professor oriente os alunos a ler o caso antecipadamente e, seja desenvolvido em sala de aula, em turmas de até cinco membros, pode variar de acordo com o tamanho, em um período de duração de duas horas/aula. Portanto, a figura 1 propõe uma agenda sintetizada para a discussão do caso.

Quadro 1- Agenda para discussão do caso.

\begin{tabular}{|c|l|}
\hline $\begin{array}{c}\text { Tempo de } \\
\text { duração }\end{array}$ & \multicolumn{1}{c|}{ Atividades } \\
\hline $15 \mathrm{~min}$ & $\begin{array}{l}\text { Apresentação geral do caso com direcionamento às teorias para orientação e formação dos grupos } \\
\text { para discussão. }\end{array}$ \\
\hline $20 \mathrm{~min}$ & $\begin{array}{l}\text { Contextualização do caso para ensino com exposição das questões e suas respectivas fundamentações } \\
\text { teóricas e associação da literatura. }\end{array}$ \\
\hline $40 \mathrm{~min}$ & Apresentação e discussão das respostas propostas por cada grupo. \\
\hline $30 \mathrm{~min}$ & Desenvolvimento e apresentação da solução para o dilema do caso conforme as teorias apresentadas. \\
\hline $15 \mathrm{~min}$ & Conclusões. \\
\hline
\end{tabular}

Fonte: autoria própria (2017)

\section{Questões para discussão e análise teórica do caso}

Sugere-se que o professor, seguindo o planejamento proposto no quadro 1, apresente os questionamentos a seguir:

Questão 1:O empresário apresenta características empreendedoras? Se sim, em que momento é possível identificá-los?

\begin{tabular}{|c|l|c|}
\hline CONSTRUTO & \multicolumn{1}{c|}{ CONCEITOS } & AUTOR (ES) \\
\hline \multirow{5}{*}{$\begin{array}{c}\text { Características } \\
\text { Empreendedoras }\end{array}$} & $\begin{array}{l}\text { O empreendedor é a pessoa que identifica oportunidades e } \\
\text { cria algo inovador sob condições de incerteza, assumindo os } \\
\text { riscos envolvidos, imbuídos de persistência e visão de futuro. }\end{array}$ & $\begin{array}{c}\text { Hisrichet. } \text { al. } \\
(2009)\end{array}$ \\
\cline { 2 - 4 } & $\begin{array}{l}\text { O empreendedor é aquele que consegue visualizar uma } \\
\text { oportunidade de negócio, de sucesso, que poucos veem, } \\
\text { antecipando aos sinais de novas tendências. }\end{array}$ & $\begin{array}{c}\text { Roque } \\
\text { oportunidade de negócio, de sucesso, que poucos veem, } \\
\text { antecipando aos sinais de novas tendências. }\end{array}$ \\
\cline { 2 - 4 } & $\begin{array}{l}\text { O empreendedor é um identificador de oportunidades, que, } \\
\text { através da iniciativa, ele assume riscos calculados ao abrir } \\
\text { um negócio, agrega novos valores e transforma o contexto } \\
\text { social e econômico no qual estão inseridos. }\end{array}$ & $\begin{array}{c}\text { Dornelas } \\
\text { (2015) }\end{array}$ \\
\hline
\end{tabular}

Fonte: Elaborado pelo autor (2017).

Questão 2: De que forma as atitudes do empreendedor impactaram na consolidação do negócio?

\begin{tabular}{|c|c|c} 
CONSTRUTO & CONCEITOS & AUTOR (ES)
\end{tabular}




\begin{tabular}{|c|l|c|}
\hline \multirow{5}{*}{$\begin{array}{c}\text { Atitudes } \\
\text { empreendedoras no } \\
\text { sucesso do negócio }\end{array}$} & $\begin{array}{l}\text { A atitude empreendedora está intrinsecamente no } \\
\text { comportamento de um indivíduo que apresenta forte } \\
\text { autonomia para ação, liberdade para trabalhar, } \\
\text { detentor de potencialidades para assunção aos riscos. }\end{array}$ & $\begin{array}{c}\text { Pinchot; pellmn } \\
\text { que atuam como representações do contexto social, } \\
\text { ativando de forma imediata as crenças definidas na } \\
\text { memória do indivíduo. C }\end{array}$ \\
\cline { 2 - 3 } & $\begin{array}{l}\text { A mentalidade empreendedora é um conceito que } \\
\text { está associado à percepção e avaliação interna do } \\
\text { indivíduo sobre o ambiente no qual ele está inserido }\end{array}$ & $\begin{array}{c}\text { Oado em um sistema dinâmico que } \\
\text { e a existência de condições que podem influenciar de } \\
\text { forma positiva ou negativa na decisão de } \\
\text { empreender. }\end{array}$ \\
\hline
\end{tabular}

Fonte: Elaborado pelo autor (2017).

Questão 3: O espírito empreendedor pode ser considerado o principal motivo que impulsionou na criação do negócio?

\begin{tabular}{|c|c|c|}
\hline CONSTRUTO & CONCEITOS & AUTOR (ES) \\
\hline \multirow{3}{*}{$\begin{array}{c}\text { Espírito } \\
\text { Empreendedor }\end{array}$} & $\begin{array}{l}\text { As características do empreendedor estão relacionadas } \\
\text { com a motivação que este tem por suas atividades, já } \\
\text { que demonstram determinação e motivação } \\
\text { diferenciada, distinguindo-se dos demais profissionais, } \\
\text { que apenas entregam o mínimo exigido para o } \\
\text { cumprimento de suas tarefas. O indivíduo com } \\
\text { potencial empreendedor pode ser extremamente } \\
\text { criativo, mas sem oportunidade não conseguirá atingir } \\
\text { seus propósitos organizacionais. }\end{array}$ & $\begin{array}{c}\text { Dornelas } \\
\text { (2008) } \\
\text { Shortet al } \\
\text { (2010) }\end{array}$ \\
\hline & $\begin{array}{l}\text { A essência do empreendedorismo está centrada na } \\
\text { liberdade, porque é ela que impulsiona o ser, } \\
\text { independente do motivo que foi deflagrador do desejo } \\
\text { de empreender. }\end{array}$ & Boavaet al (2010) \\
\hline & $\begin{array}{l}\text { As características comportamentais do empreendedor } \\
\text { podem receber influências do ambiente e de forma } \\
\text { intensa alterar o curso da ação, provocando intensas } \\
\text { modificações nos propósitos iniciais do empreendedor. }\end{array}$ & $\begin{array}{l}\text { Minelloet al } \\
\text { (2011) }\end{array}$ \\
\hline
\end{tabular}

Fonte: Elaborado pelo autor (2017).

Questão 4: O que motivou Queiroz abrir um novo negócio? Oportunidade ou necessidade?

\begin{tabular}{|c|l|c|}
\hline CONSTRUTO & \multicolumn{1}{|c|}{ CONCEITOS } & AUTOR (ES) \\
\hline \multirow{4}{*}{$\begin{array}{c}\text { Empreendedores } \\
\text { por }\end{array}$} & $\begin{array}{l}\text { As oportunidades empreendedoras surgem, } \\
\text { primeiramente, porque diferentes indivíduos possuem } \\
\text { crenças diversificadas sobre o valor relativo dos } \\
\text { recursos disponíveis, aspectos culturais e econômicos. }\end{array}$ & Filion \\
\cline { 2 - 4 } Oportunidade & $\begin{array}{l}\text { Os empreendedores por necessidade representariam } \\
\text { uma parcela da população envolvida com o } \\
\text { empreendedorismo por não ter outra opção de trabalho. }\end{array}$ & Maximiano (2006) \\
\hline
\end{tabular}




\begin{tabular}{|c|c|c|}
\hline $\begin{array}{c}\text { versus } \\
\text { Empreendedores } \\
\text { por Necessidade }\end{array}$ & $\begin{array}{l}\text { A oportunidade refere-se à percepção de que há } \\
\text { oportunidades de negócio que podem ser exploradas no } \\
\text { mercado. Os empreendedores por oportunidade são } \\
\text { aqueles que identificam uma oportunidade de negócio } \\
\text { que pretende perseguir, são movidos pelo desejo de } \\
\text { realização, onde os mesmos visualizam, analisam e } \\
\text { planejam para ter sucesso. }\end{array}$ & $\begin{array}{c}\text { André } \\
(2015) \\
\text { Global Entrepreneurship } \\
\text { Monitor - GEM } \\
(2016)\end{array}$ \\
\hline
\end{tabular}

Fonte: Elaborado pelo autor (2017).

Questão 5: O negócio apresenta características inovadoras?

\begin{tabular}{|c|c|c|}
\hline CONSTRUTO & CONCEITOS & AUTOR (ES) \\
\hline \multirow{3}{*}{$\begin{array}{l}\text { Características } \\
\text { Inovadoras }\end{array}$} & $\begin{array}{l}\text { A inovação é uma característica do espírito } \\
\text { empreendedor, que, encara mudanças como } \\
\text { oportunidades, e considera essencial agregar novos } \\
\text { valores que resultem em maior satisfação. É a } \\
\text { habilidade de transformar algo já existente em um } \\
\text { recurso que gere riqueza. Qualquer mudança no } \\
\text { potencial produtor-de-riqueza de recursos já } \\
\text { inexistentes constitui inovação. }\end{array}$ & $\begin{array}{l}\text { Drucker } \\
(2008)\end{array}$ \\
\hline & $\begin{array}{l}\text { O empreendedor se diferencia de outros agentes } \\
\text { econômicos por sua necessidade de realização. Os } \\
\text { empreendedores buscam objetivos desafiantes, têm } \\
\text { preocupação com qualidade e gostam de resolver } \\
\text { problemas. }\end{array}$ & $\begin{array}{l}\text { MCclelland (1961) } \\
\text { Aveni } \\
\text { (2014) }\end{array}$ \\
\hline & $\begin{array}{l}\text { Criatividade e imaginação são ferramentas } \\
\text { fundamentais do empreendedor inovador, que possui } \\
\text { forte capacidade de associar seus conhecimentos às } \\
\text { necessidades e problemas do mercado, criando suas } \\
\text { próprias oportunidades. }\end{array}$ & $\begin{array}{c}\text { Marques } \\
(2016)\end{array}$ \\
\hline
\end{tabular}

Fonte: Elaborado pelo autor (2017).

Questão 6: Identifique as possíveis restrições que o empreendimento terá caso decida acatar a ideia do filho universitário.

\begin{tabular}{|c|c|c|}
\hline CONSTRUTO & CONCEITOS & $\overline{\text { AUTOR (ES) }}$ \\
\hline & $\begin{array}{l}\text { A exploração de uma nova oportunidade no mercado } \\
\text { envolve altos níveis de incerteza por parte do } \\
\text { empreendedor, relacionadas à probabilidade de } \\
\text { resultados negativos, que podem ocasionar falência. }\end{array}$ & $\begin{array}{l}\text { Hisrich, Peters e Shepherd } \\
\text { (2014) }\end{array}$ \\
\hline $\begin{array}{c}\text { Restrições } \\
\text { de um } \\
\text { empreendimento }\end{array}$ & $\begin{array}{l}\text { Para as empresas sobreviverem à competição global do } \\
\text { mercado, estas devem tomar decisões de forma rápida, } \\
\text { sempre direcionando suas ações para manter-se firmes } \\
\text { aos seus objetivos estratégicos. Estes pequenos } \\
\text { negócios, contudo, são vistos como vulneráveis às }\end{array}$ & $\begin{array}{c}\text { Santanaet al } \\
\text { (2016) }\end{array}$ \\
\hline
\end{tabular}




\begin{tabular}{|c|c|}
\hline \multirow[t]{2}{*}{$\begin{array}{l}\text { para implantar um } \\
\text { sistema financeiro }\end{array}$} & $\begin{array}{l}\text { incertezas do mercado, pois normalmente possuem } \\
\text { restrições operacionais e financeiras. }\end{array}$ \\
\hline & $\begin{array}{l}\text { Em um mundo onde a competitividade impera e as } \\
\text { estratégias são de extrema relevância, as organizações } \\
\text { necessitam contar com a atuação de gestores cada vez } \\
\text { mais eficientes para se sustentar no mercado. Desse } \\
\text { modo, inovar continuamente e identificar lacunas no } \\
\text { ambiente empresarial são fundamentais. }\end{array}$ \\
\hline
\end{tabular}

Fonte: Elaborado pelo autor (2017).

Questão 7: Quais os riscos envolvidos no processo de tomada de decisão?

\begin{tabular}{|c|c|c|}
\hline CONSTRUTO & CONCEITOS & AUTOR (ES) \\
\hline \multirow{3}{*}{$\begin{array}{c}\text { Riscos no } \\
\text { processo de } \\
\text { tomada de decisão }\end{array}$} & $\begin{array}{l}\text { As decisões estão estruturadas em estratégicas, que } \\
\text { tendem a ser tomadas a partir de situações provocadas } \\
\text { pela empresa e o ambiente. As decisões táticas estão } \\
\text { relacionadas a estruturação dos recursos da empresa. As } \\
\text { decisões operacionais que visam maximizar a eficiência } \\
\text { do processo de conversão dos recursos. }\end{array}$ & $\begin{array}{l}\text { Ansoff } \\
\text { (1977) }\end{array}$ \\
\hline & $\begin{array}{l}\text { A tomada de decisão é fundamental, seja em nível } \\
\text { organizacional, ou em nível pessoal, pesquisadores } \\
\text { teóricos e empíricos e administradores se esforçam para } \\
\text { aperfeiçoar sua compreensão sobre o processo de } \\
\text { tomada de decisões. }\end{array}$ & $\begin{array}{l}\text { Martins } \\
(2013)\end{array}$ \\
\hline & $\begin{array}{l}\text { Para manter a empresa no mercado é necessário } \\
\text { conhecer os fatores referentes à atividade da empresa, } \\
\text { monitorando a necessidade do mercado, os concorrentes } \\
\text { e o comportamento dos consumidores, para viabilizar o } \\
\text { alinhamento de estratégias e promover a adaptabilidade. }\end{array}$ & $\begin{array}{l}\text { Baron e Scott } \\
\quad(2015)\end{array}$ \\
\hline
\end{tabular}

Fonte: Elaborado pelo autor (2017).

Questão 8: Quais estratégias podem ser adotadas para fidelizar e reter novos clientes, frente à crise do país?

\begin{tabular}{|c|c|c|}
\hline CONSTRUTO & CONCEITOS & AUTOR (ES) \\
\hline \multirow{2}{*}{$\begin{array}{l}\text { Adoção de } \\
\text { Estratégias } \\
\text { capazes de } \\
\text { aumentar o }\end{array}$} & $\begin{array}{l}\text { O custo para se conseguir um cliente novo é, em média, } \\
\text { cinco a sete vezes maior do que o custo para manter um } \\
\text { cliente já existente. Muitas empresas sabem o custo de } \\
\text { se obter novos clientes, porém não sabem o custo de } \\
\text { perdê-los. Gerir a lealdade dos clientes torna-se um } \\
\text { componente fundamental para se assegurar a saúde, } \\
\text { inclusive financeira, de uma organização. }\end{array}$ & $\begin{array}{l}\text { Wing } \\
(1998) \\
\text { Gerson } \\
(1999)\end{array}$ \\
\hline & $\begin{array}{l}\text { As organizações que possui alto índice de retenção de } \\
\text { clientes e alta lucratividade por cliente procuram o } \\
\text { produto ou serviço certo, para o cliente certo, pelo } \\
\text { preço certo, na hora certa, pelos canais certos. }\end{array}$ & $\begin{array}{l}\text { Swift } \\
(2001)\end{array}$ \\
\hline
\end{tabular}


número de

Quanto mais se identifica as necessidades dos clientes,

Carvalho, Maia E Santos(2012). clientes maior a tendência de torná-lo fiel.

Fonte: Elaborado pelo autor (2017).

Questão 9: $O$ empreendedor deve ser capaz de reagir às mudanças independentemente do contexto financeiro?

\begin{tabular}{|c|l|c|}
\hline CONSTRUTO & \multicolumn{1}{|c|}{ CONCEITOS } & \multicolumn{1}{|c|}{ AUTOR (ES) } \\
\hline & $\begin{array}{l}\text { Os empreendedores estão sempre buscando mudanças, } \\
\text { reagem a elas e a exploram como sendo uma } \\
\text { oportunidade, nem sempre vista pelos demais. }\end{array}$ & \multicolumn{1}{c|}{$\begin{array}{c}\text { Drucker } \\
\text { Reagir a mudanças }\end{array}$} \\
\cline { 2 - 4 } $\begin{array}{c}\text { A análise estratégica da empresa deve incluir um misto } \\
\text { fe racionalidade e subjetividade, seguindo um processo } \\
\text { financeiro }\end{array}$ & $\begin{array}{l}\text { básico, que pode ajudar o empreendedor a entender } \\
\text { melhor a situação e seu negócio e quais as melhores } \\
\text { alternativas ou meios para atingir os objetivos e metas } \\
\text { estipulados. }\end{array}$ & $\begin{array}{c}\text { Dornelas (2008) } \\
\text { O empreendedor evolui por meio de um processo } \\
\text { constante de tentativas e erros. Seu avanço acontece a } \\
\text { partir das descobertas que faz, as quais podem se referir } \\
\text { a uma infinidade de elementos. Esses elementos, } \\
\text { combinados adequadamente, o habilitam a transformar } \\
\text { uma simples e mal estruturada ideia em algo concreto e } \\
\text { bem-sucedido no mercado. }\end{array}$ \\
\hline
\end{tabular}

Fonte: Elaborado pelo autor (2017).

Questão 10: Mesmo com visões distintas, no caso do empreendedor e do filho caçula, é possível alinhar as opiniões de ambos e tornar o negócio mais lucrativo e organizado. Quais as forças, fraquezas, ameaças e oportunidades (swot) que devem ser levadas em consideração para tomar uma decisão em relação a investir ou não no sistema financeiro?

\begin{tabular}{|c|l|c|}
\hline CONSTRUTO & \multicolumn{1}{|c|}{ CONCEITOS } & \multicolumn{1}{c|}{ AUTOR (ES) } \\
\hline & $\begin{array}{l}\text { Possibilita a escolha de uma estratégia adequada para } \\
\text { que se alcancem determinados objetivos a partir de uma } \\
\text { avaliação crítica dos ambientes internos e externos. A } \\
\text { matriz SWOT é uma das práticas mais comuns nas } \\
\text { empresas voltadas para o pensamento estratégico e } \\
\text { Matriz }\end{array}$ & $\begin{array}{l}\text { (2004) } \\
\text { marketing, a prática pode permitir uma melhor visão de } \\
\text { negócios. }\end{array}$ \\
\hline
\end{tabular}




\begin{tabular}{|c|c|c|}
\hline \multirow[t]{2}{*}{ SWOT } & $\begin{array}{l}\text { É necessário que a empresa foque no mercado no qual } \\
\text { atua, voltando sua atenção a todas as possíveis } \\
\text { variações dos fatores que influenciam a rentabilidade da } \\
\text { empresa, de modo a aumentar seu nível de } \\
\text { adaptabilidade. }\end{array}$ & $\begin{array}{l}\text { Porter } \\
\text { (2004) }\end{array}$ \\
\hline & $\begin{array}{l}\text { A SWOT serve para posicionar ou verificar a situação } \\
\text { e a posição estratégica da empresa no ambiente em que } \\
\text { atua. }\end{array}$ & $\begin{array}{c}\text { MCcreadie } \\
\text { (2008) }\end{array}$ \\
\hline
\end{tabular}

Fonte: Elaborado pelo autor (2017).

\section{Questão 11: De que maneira as experiências do empreendedor influenciaram na gestão} do negócio?

\begin{tabular}{|c|l|c|}
\hline CONSTRUTO & \multicolumn{1}{|c|}{ CONCEITOS } & \multicolumn{1}{|c|}{ AUTOR (ES) } \\
\hline \multirow{2}{*}{$\begin{array}{c}\text { Experiências } \\
\text { antigas como } \\
\text { influenciador ao } \\
\text { negócio atual }\end{array}$} & $\begin{array}{l}\text { As experiências anteriores do empreendedor fornecem } \\
\text { as habilidades administrativas necessárias para } \\
\text { potencializar o desempenho empresarial. }\end{array}$ & $\begin{array}{c}\text { Hisrich, Peters e Shepherd } \\
\text { A identificação de oportunidade depende da habilidade } \\
\text { do empreendedor, e, apesar de não existir técnicas, } \\
\text { requer vasto conhecimento sobre o mercado e o } \\
\text { empreendimento. }\end{array}$ \\
\cline { 2 - 3 } & $\begin{array}{l}\text { Ser empreendedor é mais do que criar novos negócios, } \\
\text { novos produtos, novas oportunidades, é um estilo de } \\
\text { vida, uma decisão de vida. Decisão de agir, de buscar a } \\
\text { felicidade, a sua realização pessoal, seus sonhos de } \\
\text { tomar em suas mãos as rédeas da sua vida e do seu } \\
\text { destino e, ao tomar essa atitude, tem como consequência } \\
\text { o sucesso pessoal e profissional. }\end{array}$ & \multicolumn{1}{c|}{$\begin{array}{c}\text { Dolabela } \\
\text { (2008) }\end{array}$} \\
\hline
\end{tabular}

Fonte: Elaborado pelo autor (2017).

Questão 12: Uma empresa familiar pode se limitar ao âmbito da gestão?

\begin{tabular}{|l|l|c|}
\hline CONSTRUTO & \multicolumn{1}{|c|}{ CONCEITOS } & AUTOR (ES) \\
\hline & $\begin{array}{l}\text { Empresas familiares são geralmente proativas, dispostas a } \\
\text { assumir riscos calculados e são inovadoras. No entanto, } \\
\text { algumas empresas familiares podem perder o seu zelo } \\
\text { empreendedor, por que os membros da família geralmente } \\
\text { dominam a tomada de decisões e controlam o fluxo de }\end{array}$ & Zahra \\
& $\begin{array}{l}\text { informações, excluindo os membros não familiares, } \\
\text { reduzindo a variedade de fluxos de conhecimento a partir } \\
\text { de fontes externas, bem como oportunidades de }\end{array}$ & $(2012)$ \\
& aprendizado e empreendedorismo. & \\
\hline
\end{tabular}




\begin{tabular}{|l|l|c|}
\hline \multirow{5}{*}{\begin{tabular}{|l} 
Empresa \\
Familiar
\end{tabular}} & $\begin{array}{l}\text { O processo de sucessão é essencial para a sobrevivência de } \\
\text { uma empresa familiar.A participação dos envolvidos é um } \\
\text { dos métodos mais indicados, o qual pode ser realizado meio } \\
\text { de reuniões de família, na busca de facilitar o } \\
\text { desenvolvimento de valores partilhados, possibilitando } \\
\text { uma maior segurança na tomada de decisão. }\end{array}$ & $\begin{array}{c}\text { Freire et al. } \\
(2010) \\
\text { Mussolino e Calabro } \\
(2014)\end{array}$ \\
\cline { 2 - 3 } & $\begin{array}{l}\text { O processo de profissionalização na empresa familiar pode } \\
\text { ser uma das formas pela qual as estratégias de gestão se } \\
\text { formalizam à medida que a empresa cresce Nesse sentido, } \\
\text { a família tem um papel ativo em planejar a sucessão e } \\
\text { profissionalizar a empresa, de forma a minimizar conflitos } \\
\text { e escolher como sucessor um profissional que tenha } \\
\text { recebido formação adequada para assumir o comando da } \\
\text { empresa }\end{array}$ & $\begin{array}{c}\text { Rodrigues } \text { et al } \\
(2004) \\
\text { EstoL e Ferreira } \\
(2006)\end{array}$ \\
\hline
\end{tabular}

Fonte: Elaborado pelo autor (2017). 


\section{REFERÊNCIAS}

ANDRÉ, A. J. Ser empreendedor com base em processo de inovação competitivo. 2015. 173 f. Tese (Mestrado em Gestão e Empreendedorismo) - Instituto Superior de Contabilidade e Administração de Lisboa. 2015.

ANSOFF, H.I. Estratégia empresarial. São Paulo: McGraw Hill, 1977.

BARON, R. A.; SCOTT, A. S. Empreendedorismo: Uma visão do processo. São Paulo: Cengage Learning, 2015.

BOAVA, D.; MACÊDO, F.; LOPES, P. Percepções de empresários incubados face ao contexto empreendedor. In: Encontro anual da ANPAD, 30, 2006, Salvador. Anais... Salvador: ANPAD, 2006.

CARVALHO, A. L. L.; MAIA, C. A.; SANTOS, M. C. Captação e retenção de clientes:BSB produtora de equipamentos de proteção individual. Lins, p. 54, 2012.

DOLABELA, F. Oficina do Empreendedor. Rio de Janeiro: Sextantes, 2008.

DORNELAS, J. C. A. Empreendedorismo: transformando ideias em negócios. 3. Ed. Rio de Janeiro: Elsevier, 2008.

DORNELAS, J. C. A. Empreendedorismo: transformando ideias em negócios. Rio de Janeiro: Empreende/LTC, 2015.

DRUCKER, P. F. Inovação e Espírito Empreendedor: Prática e Princípio. São Paulo: Cengage Learning, 2008.

DRUCKER, P. F. Inovação e espírito empreendedor. São Paulo: Pioneira, 1987.

Estol, K. M. F. \& Ferreira, M. C. (2006). O Processo sucessório e a cultura organizacional em uma empresa familiar brasileira. Revista de Administração Contemporânea - RAC, 10(4), 93- 110.

FILION, L. J. Empreendedorismo: empreendedores e proprietários-gerentes de pequenos negócios. RAUSP, São Paulo, v. 34, n. 2, p. 05-28, abr./jul. 1999.

FREIRE, P. S., Soares, A. P., Nakayama, M. K., \& Spanhol, F. J. (2010). Processo de sucessão em empresa familiar: gestão do conhecimento contornando resistências às mudanças organizacionais. Journal of Information Systems and Technology Management - JISTEM, 7(3), 713-736.

FREITAS, E. C. \& Barth, M. (2012). De pai para filho: a complexidade e os desafios da gestão das empresas familiares. Revista de Administração da UFSM, 5(3), 549-568. 
GLOBAL ENTREPRENEURSHIP MONITOR (GEM). GEM Key Indicators. London Business School, 2016. Disponível em: $\leq$ https://www.sebrae.com.br/Sebrae/Portal\%20Sebrae/Anexos/GEM\%20Nacional\%20\%20web.pdf >.Acesso em: 02 de Fevereiro de 2018.

HISRICH, R. D.; PETERS, M. P.; SHEPHERD, Dean A. Empreendedorismo. 9. ed. Porto Alegre: AMGH, 2014.

MARTINS, D. R. et al. Como se tornar um empreendedor? uma análise do processo de decisão ao empreendedorismo. Revista da UNIFEBE, v. 1, n. 20, p. 22-42, 2017.

MARTINS, D. R. Processo de decisão e empreendedorismo: Um estudo com empreendedores da Região Oeste de Santa Catarina. Disponível em: http://www.fpl.edu.br/2013/media/pdfs/mestrado/dissertacoes_2013/dissertacao_daiana_ransa n_martins_2013.pdf>Acesso em: 21 de Março de 2018.

MARQUES, J. R . 2016. Características de um empreendedorismo inovador. <Disponível em: http://www.jrmcoaching.com.br/blog/quais-as-caracteristicas-de-um-empreendedorismo-inovador/>. Acesso em: 24 de Janeiro de 2018.

MARTINS, L. Marketing: Como se tornar um profissional de sucesso. 1. ed. São Paulo: Digerati Books, 2006.

MAXIMIANO, A. C. A. Administração para empreendedores. São Paulo: Prentice Hall, 2006.

MCCREADIE, K. A Arte da Guerra SUN TZU: uma interpretação em 52 ideias brilhantes: 1. ed. São Paulo: Globo, 2008.

MINEllo, I. F.; SCHERER, L. A. L. A.; PERLIN, A. P.; AlVES, L. C.; HUEZO, M. R. Comportamento e tipologia do empreendedor diante do insucesso empresarial. In: ENCONTRO ANUAL DA ASSOCIAÇÃO NACIONAL DOS

Oliveira, J. L., Albuquerque, A. L., \& Pereira, R. D. (2013). De "filho do dono" a dirigente ilustre: caminhos e descaminhos no processo de construção da legitimidade de sucessores em organizações familiares. Revista de Administração, 48(1), 21-33

PROGRAMAS DE PÓS GRADUAÇÃO EM ADMINISTRAÇÃO, 35., 2011, Rio de Janeiro. Anais... Rio de Janeiro: ANPAD, 2011. 1 CD-ROM.

MUSSOLINO, D. \& Calabro, A. (2014). Paternalistic leadership in family firms: types and implications for intergenerational succession. Journal of Family Business Strategy, v. 5(2), p.197- 210 . 
ORR, M. G.; THRUSH,R.; PLAUT. D. C. The Theory of Reasoned Action as Parallel Constraint Satisfaction: Towards a Dynamic Computational Model of Health Behavior, v. 12, n. 19, 2013.

PINCHOT, G.; PELLMAN, R. Intraempreendedorismo na prática: um guia de inovação nos negócios. Rio de Janeiro: Campus, 2004.

RODRIGUES, M., RESENDE, L. M., \& PILATTI, L. A. (2004). O processo de sucessão nas empresas familiares de pequeno e médio porte: o desafio da continuidade. XI Simpósio de Engenharia de Produção - SIMPEP, Bauru, SP, Brasil.

ROQUE, W. 2010. Futuro planejado: empresas que estão à frente dos acontecimentos garantem faturamento crescente mesmo em épocas de vacas magras. Disponível em: $\langle$ http://revistapegn.globo.com/Empresasenegocios/0,19125,ERA482351-488,00.html $>$ Acesso em: 25 de Abril de 2018.

SANTANA, E. N.; CUNHA, L. P.; MARIZ, F. B. A. R. Indicadores de Desempenho Para Micro e Pequenas Empresas: análise da literatura e estudo de caso. XXXVI Encontro Nacional de Engenharia de Produção, João Pessoa. 2016.

SERRA, F.; TORRES, M. C. S. \& TORRES, A. P. Administração Estratégica. Rio de Janeiro: Reichmann e Affonso Editores, 2004.

SOUZA, V. A. B . Prefácio. In: LAPOLLI, Édis Mafra et. al. Ações empreendedoras. Florianópolis: Pandion, 2014.

SHORT, J. C.; DAVID J., KETCHEN, J. R.; CHRISTOPHER, L.; SHOOK, R. D. I.The Concept of Opportunity' in Entrepreneurship Research: Past Accomplishments and Future Challenges Journal of Management, v. 36, n. 1, p. 40-65, 2010.

SWIFT, R . CRM: O revolucionário marketing de relacionamento com o cliente. Tradução de Flávio Deny Steffen. Rio de Janeiro: Campus, 2001.

WERLANG, N. B.; FONSECA, Jayne. Competências Empreendedoras e Startups: um estudo com gestores de empresas embrionárias catarinenses. Revista Eletrônica de Administração e Turismo-ReAT, v. 8, n. 4, p. 851-869, 2016.

WING, M. J. Como falar com seus clientes: O guia da Arthur Andersen. Rio de Janeiro: Campus, 1998.

ZAHRA, S. A.; Organizational learning and entrepreneurship in family firms: exploring the moderating effect of ownership and cohesion. Small Business Economics, v.38(1), p. 51-65, 2012. 